\title{
Potential role of Notch1 signaling pathway in laryngeal squamous cell carcinoma cell line Hep-2 involving proliferation inhibition, cell cycle arrest, cell apoptosis, and cell migration
}

\author{
JING JIAO ${ }^{1,2}$, ZHAOBING QIN $^{1}$, SHA LI ${ }^{3}$, HONGTAO LIU ${ }^{4}$ and ZHAOMING LU ${ }^{4}$ \\ ${ }^{1}$ Department of Otorhinolaryngology, The First Affiliated Hospital of Zhengzhou University, Zhengzhou, \\ Henan 450052; ${ }^{2}$ Department of Stomatology, Zhengzhou Hospital, Zhengzhou, Henan 450003; ${ }^{3}$ Department of Stomatology, \\ The First Affiliated Hospital of Zhengzhou University, Zhengzhou, Henan $450052 ;{ }^{4}$ Laboratory for Cell Biology, \\ Department of Bioengineering of Zhengzhou University, Zhengzhou, Henan 450001, P.R. China
}

Received April 22, 2009; Accepted May 20, 2009

DOI: 10.3892/or_00000504

\begin{abstract}
Head and neck cancer is the sixth most common cancer worldwide and laryngeal cancer represents the largest subgroup. However, the molecular mechanism underlying its malignant behavior and progression is not clarified. Accumulating evidence has shown that Notch1 signaling pathway plays a central role in carcinogenesis, but its potential role in regulating the development of laryngeal carcinoma, has not been characterized. Here, we identified that Notch1 signaling pathway was activated in laryngeal carcinoma accompanied with up-regulation of Notch1 and Hes1 expression. Overexpression of Notch1 in laryngeal carcinoma cell line Hep-2 led to suppression of tumor cellular proliferation and arrested cell cycle in the $G_{0} / G_{1}$ phase and induced cell apoptosis, which were coupled with the down-regulation of cyclin D1, cyclin E, cdk2 and bcl-2 and up-regulation of caspase-3, caspase- 9 and p53. Most importantly, up-regulation of Notch1 expression also reduced the migration of Hep-2 cells, which was closely associated with down-regulation of MMP-2 and MMP-9. The finding may lay a foundation for further investigations into the Notch1 signaling pathway as a potential target for laryngeal carcinoma.
\end{abstract}

\section{Introduction}

Head and neck cancer is the sixth most common form of cancer worldwide (1). More than $90 \%$ of head and neck cancers are squamous cell carcinomas. The oral cavity is the

Correspondence to: Professor Zhaobing Qin, Department of Otorhinolaryngology, The First Affiliated Hospital of Zhengzhou University, 40 Daxue Road, Zhengzhou, Henan 450052, P.R. China E-mail: qin_zhaobing@126.com

Key words: Notch1 signaling pathway, laryngeal carcinoma cell Hep-2, cell cycle, cell apoptosis, invasion and metastasis most common site within the head and neck and the larynx is the second most common. In the last two decades, the 5-year survival of patients with laryngeal cancer has not changed dramatically (2). Additional strategies are needed to detect laryngeal cancer at an early stage in order to provide useful prognostic information for the management of laryngeal cancer. Substantial evidence has demonstrated signaling pathway play an essential role in development and progression of tumors $(3,4)$. Therefore, manipulation of signaling pathways may be a potential therapeutic strategy to control the growth of laryngeal tumors.

Notch1 is a multifunctional transmembrane receptor that plays an important role in cellular differentiation and tumorigenesis. Binding of Notch1 to any one of the Notch ligands (Delta1 and Jagged1, for example) will result in activation of the Notch1 protein (5). The activated form of Notch1 (NICD) then translocates to the nucleus and transactivates various target genes such as Hes1 (5). Activation of the Notch1 signaling pathway has been shown to inhibit growth in esophageal squmaous cell carcinoma and prostate cancer cells $(3,6)$ and induce cell apoptosis in esophageal squamous cell carcinoma, B cells and other hematopoietic lineages in vitro $(3,7)$. Moreover, transient expression of activated Notch1 by recombinant adenoviruses in small cell lung cancer cell lines has been shown to cause a profound growth arrest (8).

Notch signaling is an important mediator of growth and survival in several cancer types, with Notch pathway genes functioning as oncogenes or tumor suppressors in different cancers (9). However, so far, the Notch1 signaling pathway in laryngeal cancer has not been studied, therefore, we investigated whether Notch1 signaling pathway plays an important role in development and progression of laryngeal cancer. The purpose of this study was to establish whether there was an activated Notch1 signaling pathway in laryngeal cancer and to assess the role of Notch1 signaling pathway in development of laryngeal cancer, further, to investigate the effects of Notch1 signaling pathway on cell biology behavior of laryngeal carcinoma cell line Hep-2 cell in vitro. To our knowledge, this is the first study on the relationship between Notch 1 signaling pathway and the development and progression of laryngeal cancer. 


\section{Materials and methods}

Plasmid constructs. The human Notch1 (NICD) gene (corresponding to amino acids 1759-2556 of GenBank NM_017617) was cloned by reverse transcription-polymerase chain reaction (RT-PCR) using Notch1-specific primers (F: 5-CGCGAATTCATGCGCAAGCGCCGGCGGCAGCAT-3, R: 5-ACGGGATCCCTTGAAGGCCTCCGGAATGCG-3) (Underline showing EcoRI and BamHI, respectively) and human placenta tissue cDNA as a template, PCR was performed using LA Taq ${ }^{\mathrm{TM}}$ System (Takara, China) in 30 cycles of $94^{\circ} \mathrm{C}$ for $50 \mathrm{sec}, 58^{\circ} \mathrm{C}$ for $120 \mathrm{sec}$ and $72^{\circ} \mathrm{C}$ for $90 \mathrm{sec}$ and inserted into the pCLXSN and EGFP-C1 vectors using standard molecular biology techniques, producing pCLXSN-Notch1 and EGFP-C1-Notch1, respectively.

Retroviral infection, selection of stable cell clones and EGFP-C1-Notch1 vector transfection. Retroviral supernatants were produced by transfection of the PT67 packaging cell line with retroviral plasmids using Lipofectamine Plus Reagent (Invitrogen, Carlsbad, CA). The 48-hour posttransfection supernatant was harvested and filtered and polybrene $(4 \mu \mathrm{g} / \mathrm{ml})$ was added and used to infect laryngeal squamous cell carcinoma Hep-2 cells. Stable cell clones were selected using $600 \mu \mathrm{g} / \mathrm{ml}$ of $\mathrm{G} 418$. In parallel, empty plasmids were used to generate vector control stable cell lines. In addition, EGFPC1 was transfected into Hep-2, after 48 h, cells were harvested and photographed.

Semi-quantitative RT-PCR. Total RNA was extracted from untreated and transfected Hep-2 cells by TRIzol reagent (Invitrogen) according to the manufacturer's instructions and then subjected to first-strand cDNA synthesis with AMV firststrand DNA synthesis kit (Biotech Co., Shanghai, P.R. China). Procedures of RT-PCR were performed according to Lu et al (3) using the primers in Table I. Semi-quantitative evaluation of band intensity was performed with Gene Tools software (UVP, Inc., Upland, USA).

Western blot analysis. The Notch1, Hes1, cyclin D1, cyclin E, cdk2, caspase-3, caspase-9, bcl-2, MMP-2, MMP-9 and B-actin antibodies were obtained from Santa Cruz (USA). Cell lysates were prepared and Western blotting were performed as described earlier (3). The molecular weights were determined with the use of prestained protein marker. Semi-quantitative band intensity evaluation was performed with Gene Tools software (UVP, Inc.).

Cell proliferation assay. CCK-8 is a sensitive non-radioactive colorimetric assay for determining the number of viable cells in cell proliferation and cytotoxicity assays. The growth rate of Hep-2 cells stably expressing NICD was measured using the CCK-8 method according to the manufacturer's instructions. Briefly, cells were seeded into 96-well plates at $\sim 5 \times 10^{3}$ cells per well for Hep- 2 cells stably expressing NICD. On the day of measuring the growth rate of Hep-2 cells, $100 \mu 1$ of spent medium was replaced with an equal volume of fresh medium containing $10 \%$ CCK-8. Cells were incubated at $37^{\circ} \mathrm{C}$ for $1-4 \mathrm{~h}$ and the absorbance was finally determined at $450 \mathrm{~nm}$ using Microplate Spectrophotometer.
Cell cycle analysis. The cells were synchronized in $\mathrm{G}_{0}$ phase by serum starvation for $24 \mathrm{~h}$ in phenol red-free RPMI with $0.1 \%$ serum. Subsequently, cells were released into complete medium containing $10 \%$ fetal bovine serum. Briefly, $1 \times 10^{6}$ of untreated and transfected Hep-2 cells were harvested at $48 \mathrm{~h}$, after treatment and washed in PBS, then fixed in $70 \%$ cold ethanol for $30 \mathrm{~min}$ at $4^{\circ} \mathrm{C}$. After three washes in cold PBS, cells were resuspended in $1 \mathrm{ml}$ of PBS solution with $40 \mu \mathrm{g}$ of propidium iodide and $100 \mu \mathrm{g}$ of RNase A for $30 \mathrm{~min}$ at $37^{\circ} \mathrm{C}$. Samples were then subjected to analysis of their DNA contents by Becton-Dickinson FACScan flow cytometer (FACScan, Becton-Dickinson, Mountain View, USA).

Apoptosis detection by flow cytometer. Untreated and transfected Hep-2 cells were trypsinized at $48 \mathrm{~h}$, washed with cold PBS and resuspended in PBS. Annexin V-FITC (BD Biosciences, USA) at final concentration of $1 \mu \mathrm{g} / \mathrm{ml}$ and $250 \mathrm{ng}$ of propidium iodide were added to a mixture containing $100 \mu 1$ of cell resuspension and binding buffer (BD Biosciences, USA) each. After cells were vortexed and incubated for $15 \mathrm{~min}$ at RT in the dark, $400 \mu \mathrm{l}$ of binding buffer was added to the mixture for flow cytometric analysis.

In vitro cell migration assays. Migration assays were performed in a Boyden chamber system as described previously (10) with minor modifications. Briefly, effect of stably activated Notch1 signaling on migration of Hep-2 was investigated using 48-well cell culture chambers containing inserts with $8-\mu \mathrm{m}$ pores (BD PharMingen, San Diego, CA). An equal number $\left(5 \times 10^{5}\right.$ cells $\left./ \mathrm{ml}\right)$ in $50 \mu 1$ of Hep- 2 cells, Hep-2 cells stably expressing pCLXSN and pCLXSN-Notch1, respectively, were harvested and loaded into the top chamber of each well. The lower chambers were filled with either $50 \mathrm{ng} / \mathrm{ml}$ of bFGF or $0.2 \%$ BSA (negative control) in DMEM. The chambers were incubated for $6 \mathrm{~h}$ at $37^{\circ} \mathrm{C}$. At the end of the incubation period, the Matrigel and the cells on the upper surface of the filter were completely removed by wiping with a moist cotton swab. The filters were then fixed in methanol for $10 \mathrm{~min}$ and stained with hematoxylin for $2 \mathrm{~min}$. The cells at the upper surface of the filters were wiped away with a cotton swab. Migration was assayed in triplicate for each condition, in at least three independent experiments.

Statistical analysis. All experiments results were from at least three independently repeated experiments. The data were analyzed with one-way analysis of variance using SPSS version 13.0 (SPSS, Chicago, USA), as described previously (4). In all statistical analyses, a P-value $<0.05$ was considered statistically significant and all P-values were two-sided.

\section{Results}

Construction of expression vector and transfection. Total RNA isolated was reverse-transcribed to cDNA first-strand, which served as a template to amplify the target gene and a $2400 \mathrm{bp}$ of specific fragment appeared (Fig. 1A). The recovered fragments were cloned into pCLXSN and EGFP-C1 vectors to produce pCLXSN-Notch1 and EGFP-C1-Notch1, respectively. The pCLXSN-Notch1 and EGFP-C1-Notch1 vectors were identified via double enzyme-digesting method 
Table I. Primers used for semi-quantitative RT-PCR analysis.

\begin{tabular}{|c|c|c|c|c|}
\hline Genes & Primers & Size (bp) & Annealing temperature $\left({ }^{\circ} \mathrm{C}\right)$ & Accession no. \\
\hline Notch1 & $\begin{array}{l}\text { F: 5'-CAAGAAGAAGCGGCGGGAGC-3' } \\
\text { R: 5'-GCATCAGAGCGTGAGTAGCG-3' }\end{array}$ & 492 & 60 & NM_017617 \\
\hline Hes1 & $\begin{array}{l}\text { F: 5'-TCAGCGAGTGCATGAACGA-3' } \\
\text { R: 5'-AGCCTCCAAACACCTTAGCC-3' }\end{array}$ & 315 & 55 & NM_005524 \\
\hline cyclin D1 & $\begin{array}{l}\text { F: 5'-GATCAAGTGTGACCCGGACT-3' } \\
\text { R: 5'-AGAGATGGAAGGGGGAAAGA-3' }\end{array}$ & 349 & 53 & NM_053056 \\
\hline cyclin E & $\begin{array}{l}\text { F: 5'-TATACTTGCTGCTTCGGCCT-3' } \\
\text { R: 5'-TCTTTGGTGGAGAAGGATGG-3' }\end{array}$ & 368 & 50 & NM_001238 \\
\hline cdk2 & $\begin{array}{l}\text { F: 5'-TACACCCATGAGGTGACTCG-3' } \\
\text { R: 5'-AAGGGTGGTGGAGGCTAACT-3' }\end{array}$ & 552 & 52 & NM_052827 \\
\hline p53 & $\begin{array}{l}\text { F: 5'-GTGGAAGGAAATTTGCGTGT-3' } \\
\text { R: 5'-TCTGAGTCAGGCCCTTCTGT-3' }\end{array}$ & 590 & 50 & NM_000546 \\
\hline caspase-3 & $\begin{array}{l}\text { F: 5'-AGTGCTCGCAGCTCATACCT-3' } \\
\text { R: 5'-TGGCTCAGAAGCACACAAAC-3' }\end{array}$ & 535 & 55 & NM_004346 \\
\hline caspase-9 & $\begin{array}{l}\text { F: 5'-ACATCTTCAATGGGACCAGC-3' } \\
\text { R: 5'-GCATTAGCGACCCTAAGCAG-3' }\end{array}$ & 376 & 57 & NM_001229 \\
\hline bcl-2 & $\begin{array}{l}\text { F: 5'-GGATGCCTTTGTGGAACTGT-3' } \\
\text { R: 5'-GGTGCTTGGCAATTAGTGGT-3' }\end{array}$ & 457 & 53 & NM_000633 \\
\hline MMP-2 & $\begin{array}{l}\text { F: 5'-TACAAAGGGATTGCCAGGAC-3' } \\
\text { R: 5'-TGTCCTTCAGCACAAACAGG-3' }\end{array}$ & 441 & 54 & NM_004530 \\
\hline MMP-9 & $\begin{array}{l}\text { F: 5'-GATGACGAGTTGTGGTCCCT-3' } \\
\text { R: 5'-GCCTTGGAAGATGAATGGAA-3' }\end{array}$ & 273 & 50 & NM_004994 \\
\hline ß-actin & $\begin{array}{l}\text { F: 5'-GCATCCTCACCCTGAAGTAC-3' } \\
\text { R: 5'-TTCTCCTTAATGTCACGCAC-3' }\end{array}$ & 457 & 55 & NM_001101 \\
\hline
\end{tabular}
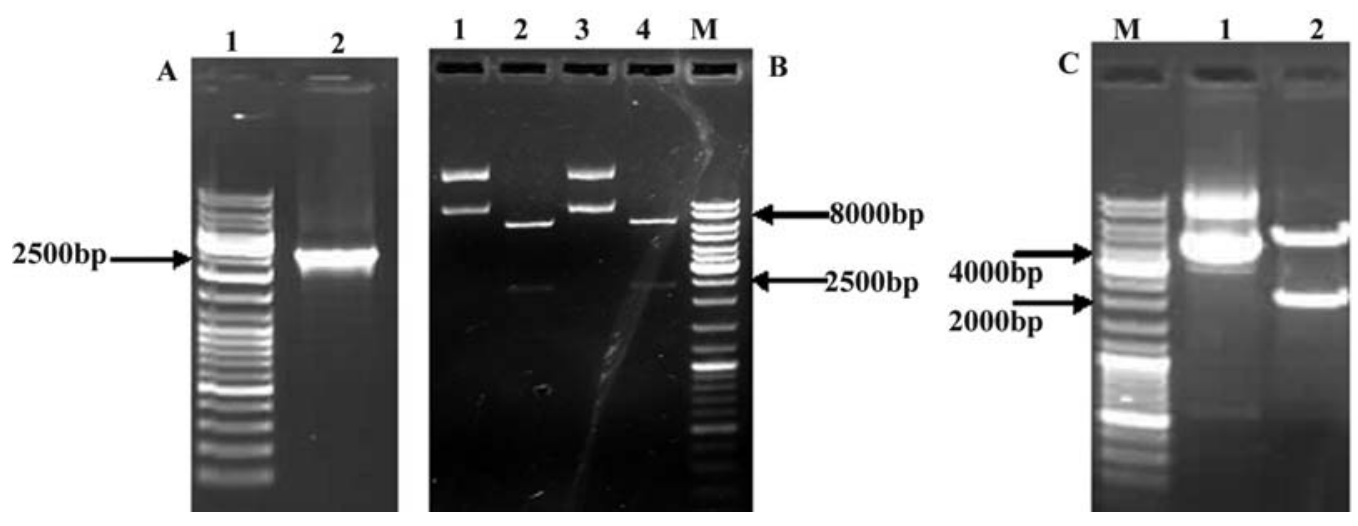

Figure 1. Constructions of retroviral plasmids pCLXSN-Notch1 and eukaryotic expression vector EGFP-C1-Notch1. (A) Amplification of Notch1 gene from human placenta tissue by RT-PCR, 1. Molecular marker, 2. Amplification of Notch1 gene; (B) Construction of retroviral plasmids pCLXSN-Notch1, 1 and 3, plasmids control, 2 and 4, Double enzyme digesting with EcoRI and BamHI, M, Molecular marker; (C) Contruction of eukaryotic expression vector EGFP-C1Notch1, M, Molecular marker, 1, plasmid control, 2, Double enzyme digesting with EcoRI and BamHI.

to be the expected size (Fig. 1B and C) and the results of DNA sequencing were completely identical to the Notch1 sequences on GenBank.

Notch1-Hes1 signaling pathway activated in Hep-2 cells. To observe whether Notch1 signaling pathway exists and its activation status in Hep-2 cells untreated and transfected with pCLXSN and pCLXSN-Notch1, Notch1 and Hes1 mRNAs and proteins expression levels were determined, respectively, by RT-PCR and Western blotting. Notch1 localization was investigated using inverted fluorescence microscopy. Expression of Notch1 protein was found both in the cytosol and nuclei of the cells transfected with EGFP-C1-Notch1 using inverted fluorescence microscropy (Fig. 2A and B), suggesting that Notch1 signaling pathway is activated. Furthermore, the results of RT-PCR and Western blotting 

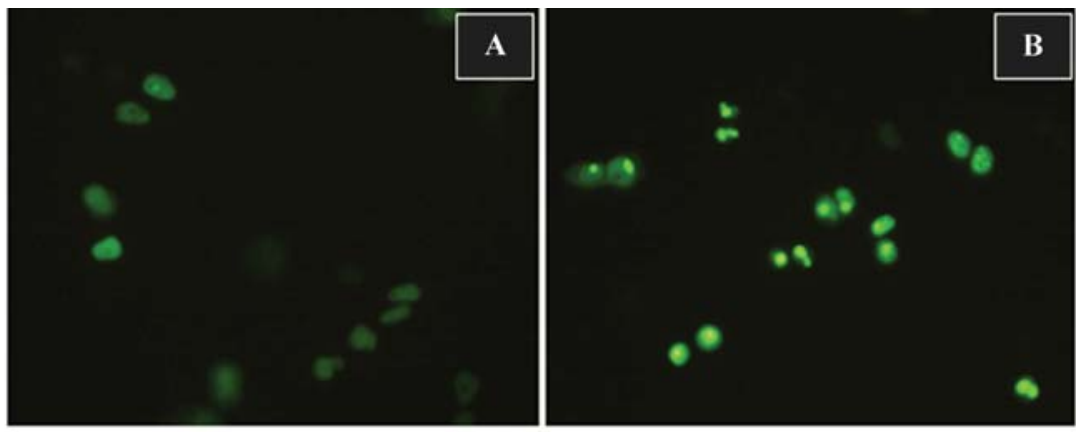

C

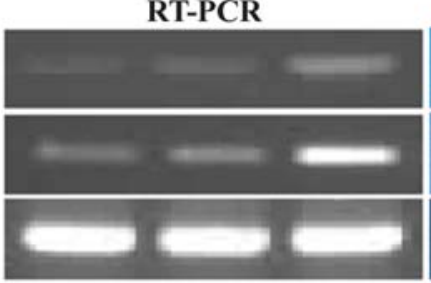

Western blotting
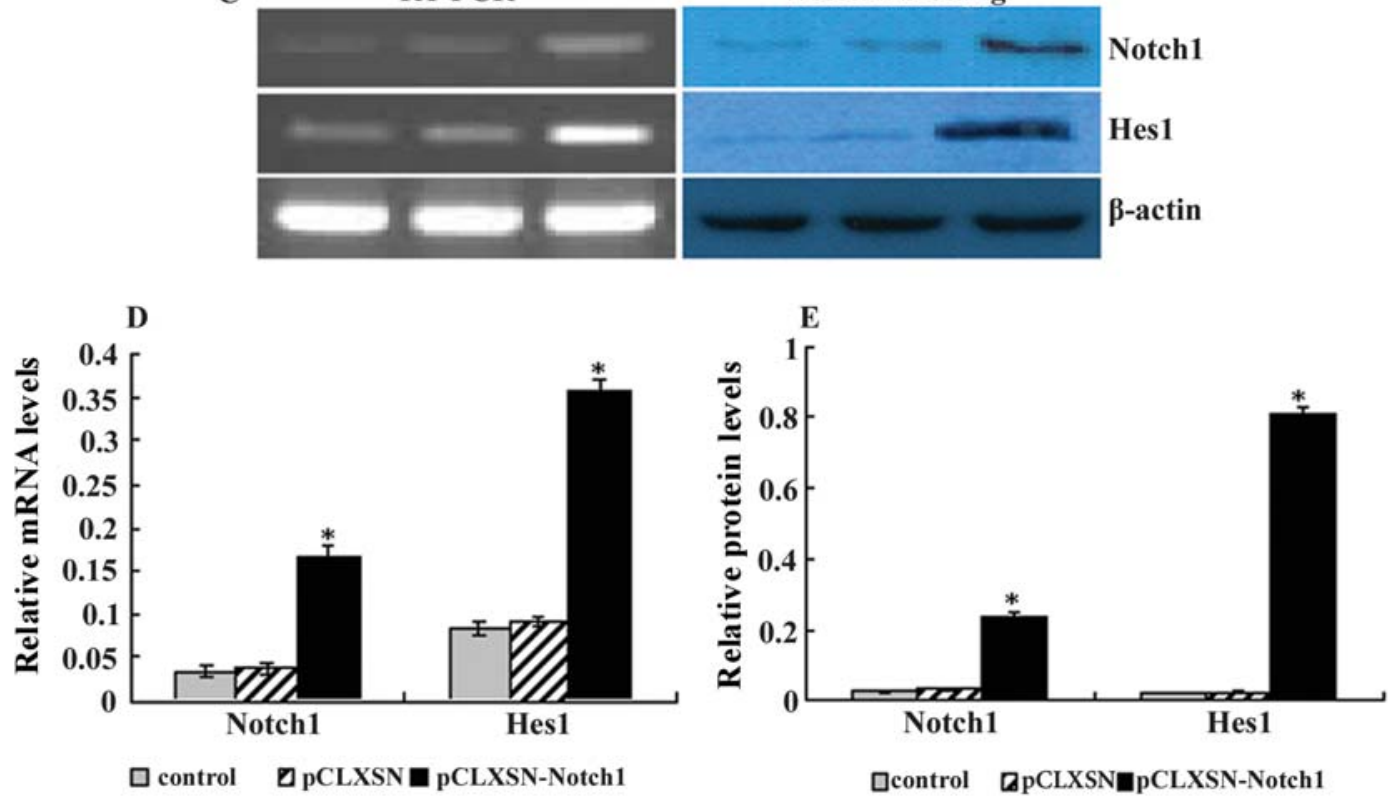

Figure 2. Foreign Notch1 gene can activate the Notch1 signaling pathway in laryngeal carcinoma cell line Hep-2. (A) pEGFP-C1 control was transfected into Hep-2 cells, showing cytoplasm expression of Notch1 gene (x400 magnification); (B) pEGFP-C1-Notch1 was transfected into HepG cells, indicating nuclear expression of Notch1 gene (x400 magnification); (C) RT-PCR and Western blotting results of Notch1 and Hes1 genes; (D) Analysis of Notch1 and Hes1 relative mRNA levels; (E) Analysis of Notch1 and Hes1 relative protein levels.

revealed that expression levels of Notch1 mRNA and protein were significantly higher $(\mathrm{P}<0.01)$ in the cells transfected with pCLXSN-Notch1 than in the cells untreated or transfected with pCLXSN (Fig. 2C-E), but there was no difference $(\mathrm{P}>0.05)$ in the expression level of Notch1 between the cells untreated and transfected with pCLXSN (Fig. 2C-E). In addition, expression of downstream target gene Hes1 was in accordance with that of Notch1 (Fig. 2C-E). Thus, it is likely that Notch1 signaling pathway may be activated by introducing extraneous Notch1 fragment into Hep-2 cells.

Activation of Notch1 signaling pathway inhibits the proliferation of Hep-2 cells. The effect of actived Notch1 on proliferation of Hep-2 cells was investigated using CCK-8 kit. As shown in Fig. 3, there was no difference $(\mathrm{P}>0.05)$ in cellular proliferation rate between the control and cells transfected with pCLXSN. However, after transfection with pCLXSN-Notch1, proliferation of the Hep-2 cells was inhibited significantly $(\mathrm{P}<0.01)$ compared to that of the control cells and transfected with pCLXSN. These findings suggest that the activated Notch1 signaling pathway is able to inhibit proliferation of Hep-2 cells.

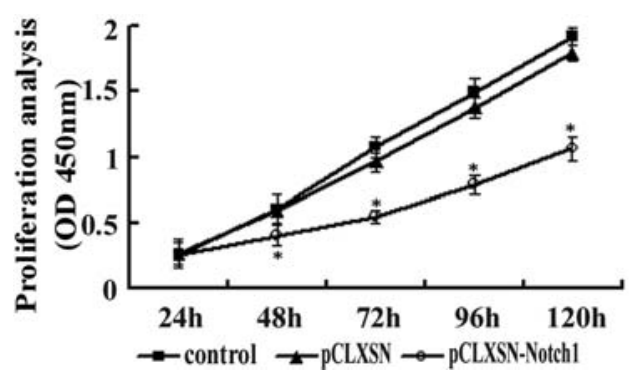

Figure 3. Activation of Notch1 signaling inhibits the proliferation of Hep-2 cells. Growth of Hep-2 cells transiently expressing Notch1 (NICD) was detected by CCK-8 kit. Hep-2 cells transfected with pCLXSN-Notch1 had a decreased growth rate that was significantly different from the control Hep-2 cells and cells transfected with pCLXSN $(\mathrm{P}<0.01)$. ${ }^{*} \mathrm{P}<0.05$, compared to those of the control Hep-2 cells and transfected with pCLXSN.

Activation of Notch1 signaling pathway arrests cell cycle at $G_{0} / G_{I}$ phase. Cell cycle analysis was performed using flow cytometry, the result demonstrated that activation of Notch1 signaling pathway could markedly enhance cell numbers in $\mathrm{G}_{0} / \mathrm{G}_{1}$ phase (Fig. 4A and B), suggesting that activation of 

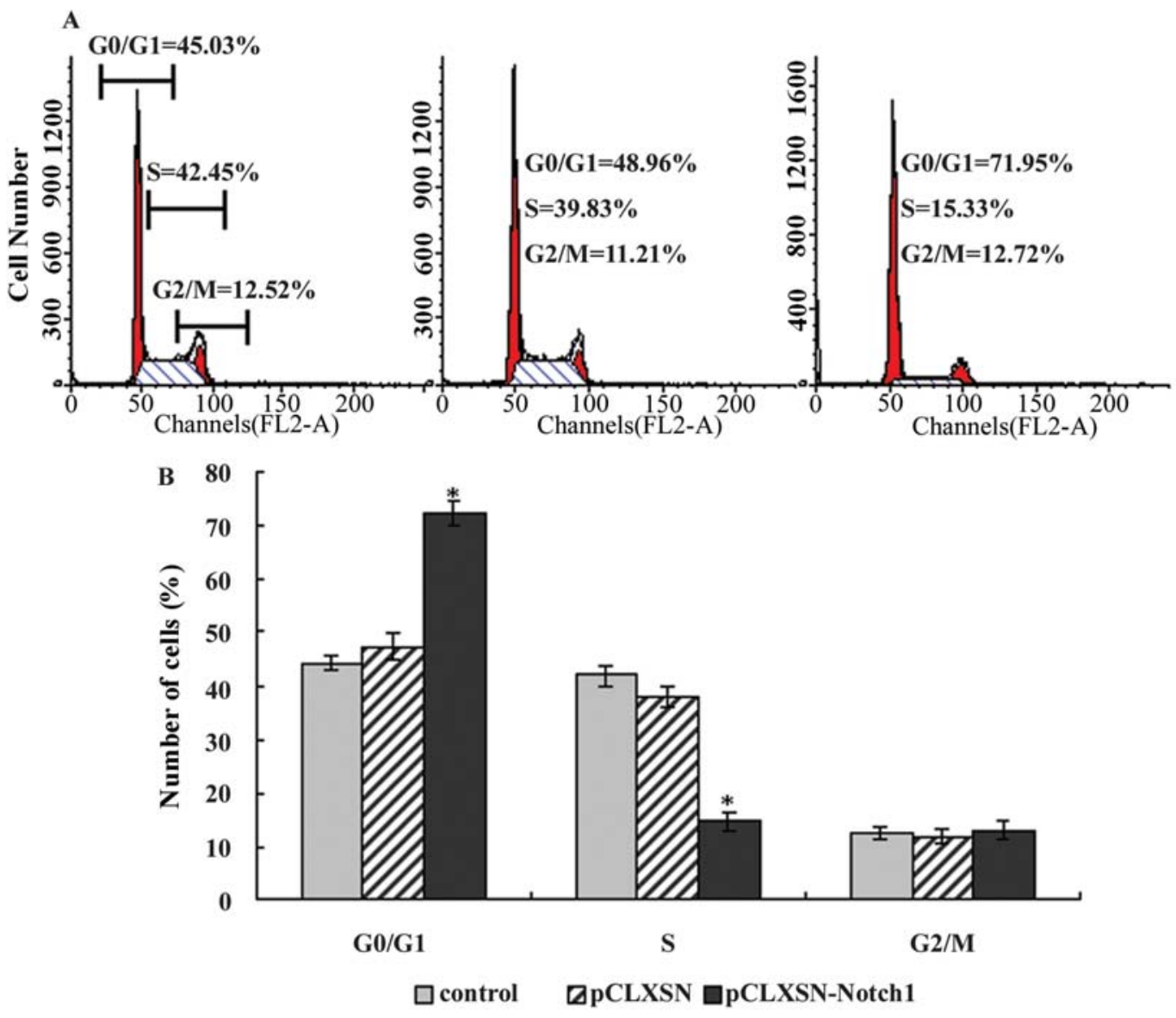

C

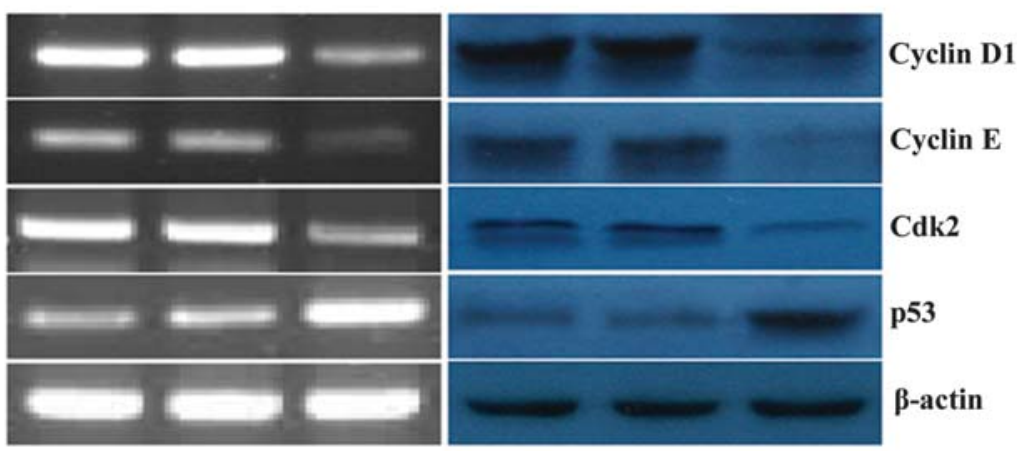

D

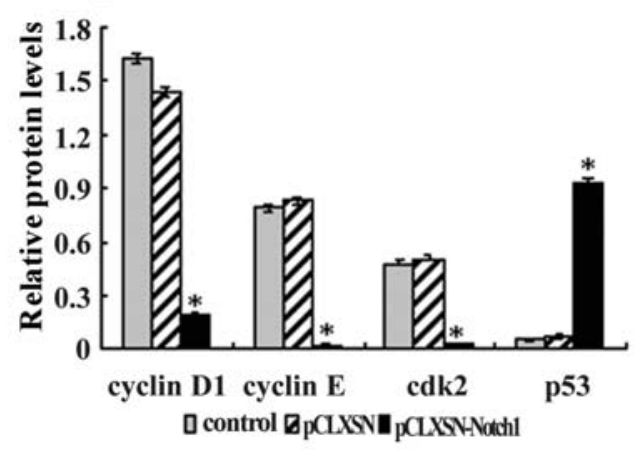

E

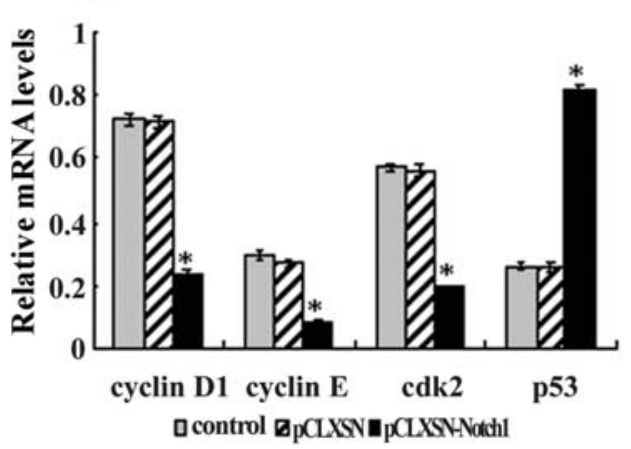

Figure 4. Activation of Notch1 signaling pathway arrests cell cycle at $\mathrm{G}_{0} / \mathrm{G}_{1}$ phase. Hep-2 cells untreated and transfected with pCLXSN and pCLXSN-Notch1 were seeded in 6-well plates containing 10\% FBS-RPMI-1640 and harvested at $48 \mathrm{~h}$, respectively, cell cycle analysis were performed with flow cytometry, genes involved with cell cycle kinetics were investigated by RT-PCR and Western blotting methods. (A) Activation of Notch1 signaling arrests cell cycle at $\mathrm{G}_{0} / \mathrm{G}_{1}$ phase in Hep-2 cells. (B) Results derived from three independent experiments are expressed as means \pm SD. (C) RT-PCR and Western blotting analysis for cyclin D1, cyclin E, cdk2 and p53 expression in Hep-2 cells. (D) Semi-quantitative values of mRNA levels of cyclin D1, cyclin E, cdk2 and p53 to ß-actin, respectively. (E) Semi-quantitative values of protein levels of cyclin D1, cyclin E, cdk2 and p53 to ß-actin, respectively. RT-PCR and Western blotting results were from three independently repeated experiments, which were statistically analyzed by densitometry using Gene Tools software, and are expressed as means \pm SD. ${ }^{*} \mathrm{P}<0.05$, compared to those of Hep- 2 cells untreated and transfected with pCLXSN. Results of one representative experiment are reported. Levels of $\beta$-actin are shown for equal loading conditions. 
Notch1 signaling pathway could arrests cell cycle at $\mathrm{G}_{0} / \mathrm{G}_{1}$ phase. Furthermore, a large number of genes involved with cell cycle kinetics were investigated by RT-PCR and Western blotting methods. The results revealed that expression of cyclin D1, cyclin E and cdk2 mRNA and proteins were obviously up-regulated compared to control cells and transfected with blank vector, whereas expression of p53 showed inverse results (Fig. 4C-E). These findings suggest that cell cycle changes may be tightly correlated with relevant cell cycle molecular marker, such as cyclin D1, cyclin E, cdk2 and p53.

Activation of Notch1 signaling pathway induces cell apoptosis. We observed a significant increase in apoptosis rates in Hep-2 cells treated with pCLXSN-Notch1 using flow cytometry (Fig. 5A and $\mathrm{B})(\mathrm{P}<0.05)$, compared to control cells and transfected with blank vector; however, there was no difference between control cells and transfected with blank vector $(\mathrm{P}>0.05)$. Further, we investigated changes of the molecules that are known to regulate and execute apoptosis, such as caspase-3, caspase-9 and bcl-2. As indicated in Fig. 5C-E, there was an obvious increase in the levels of caspase- 3 and caspase- 9 expression in Hep-2 cells stably expressing Notch1. Whereas, the expression of Bcl-2 was markedly inhibited $(\mathrm{P}<0.05)$, these findings demonstrated that Notch1induced cell apoptosis was tightly correlated with the changes of molecules above.

Activation of Notch1 signaling pathway inhibits migration in Hep-2 cells. Migration of Hep-2 cells was examined using $8-\mu \mathrm{m}$ pore membranes in Hep- 2 cells untreated and transfected with pCLXSN and pCLXSN-Notch1 in a modified Boyden chamber system. Compared to Hep-2 cells untreated and transfected with pCLXSN, migration of Hep-2 cells transfected with pCLXSN-Notch1 was significantly decreased $(\mathrm{P}<0.05)$, whereas, there was no difference between Hep-2 cells untreated and transfected with pCLXSN (P>0.05) (Fig. 6A). MMPs are involved in extracellular matrix degradation, which facilitates tumor cell invasion, therefore, in this study, the expression of MMP-2 and MMP-9 mRNAs and proteins was examined by RT-PCR and Western blotting methods. The results revealed that expressions of MMP-2 and MMP-9 were markedly increased in Hep-2 cells stably expressing Notch1, compared to untreated cells and Hep-2 cells stably expressing pCLXSN $(\mathrm{P}<0.05)$ (Fig. 6B-D). These data indicate that a decrease of migration ability in Hep-2 cells was related to downregulations of MMP-2 and MMP-9.

\section{Discussion}

Notch signaling is a highly conserved pathway, implicated in cell-fate decisions and differentiation of epithelial, neuronal, bone, blood, muscle and the development of cancer. At present, the studies on the molecular basis of Notch1 signaling pathway involved in the development of tumors are rapidly expanding. More and more evidence has indicated that Notch1 signaling pathway plays a critical role in a number of cancers, including human cancers of the breast, cervix, colon, pancreas, prostate, brain and esophagus (3,11-16). Information gleaned from the relationships between Notch1 signaling pathway and other cancers suggests that Notch1 signaling pathway may play a prominent role in development of laryngeal cancer. Therefore, current knowledge on the importance of the Notch1 signaling pathway in laryngeal cancer remains to be fully explored, which underscores the importance of understanding the basic mechanisms of Notch1 signaling pathway in the development of laryngeal cancer. In this study, we demonstrated that Notch1 signaling pathway is activated in human laryngeal cancer through introducing of foreign Notch1 NICD. Further, effect of foreign Notch1 on cell proliferation, cell cycle, apoptosis, migration of laryngeal carcinoma cell lines Hep-2 cells and its related molecular mechanisms were investigated; to clarify the role of Notch1 signaling pathway in laryngeal cancer.

Currently, there are two kinds of activations of Notch1 signaling pathway. Binding of Notch1 receptor and ligands (Jagged1, Jagged2, Delta1 and Delta4) can lead to activation of Notch1 signaling pathway; and introducing of extraneous Notch1 can also give rise to the same effects. In the current study, our findings emphasized that introduction of Notch1 NICD into Hep-2, a laryngeal cell line, could elevate the expression of the Notch1 gene, accompanied by increased downstream target gene Hes1 mRNA and protein level, meanwhile, we have demonstrated that NICD accumulated in the cytosol and nuclei of Hep-2 cells, implying that the Notch1 signaling pathway can be activated in laryngeal cancer cells by introducing extraneous Notch1 fragment.

Cell proliferation was closely correlated with the inhibition of expressions of cell cycle related genes, such as cyclinD1, cyclin E, cdk2, cdk4, etc. Progression through the various phases of cell cycle is mediated by CDKs in complex with specific cyclins (17). Many reports have revealed that cell cycle is abnormally regulated by aberrant expression of key cyclins and CDKs (18-21). Well-characterized Notch1 signaling pathway induced cell cycle arrest at different cancers, including esophageal squamous cell carcinoma (3), B cells (7), small cell lung carcinoma (SCLC) (8), and breast cancer (11). However, effect of Notch1 signaling pathway on cell proliferation and cell cycle in laryngeal cancer cells remains ill-defined, our data showed that Notch 1 could markedly inhibit cell proliferation in Hep-2 cells, further the results of flow cytometry suggested that Notch1 could arrest cell cycle at $\mathrm{G}_{0} / \mathrm{G}_{1}$ phases. In order to further investigate a mechanism for Notch1-induced cell cycle inhibition in Hep-2 cells, we analyzed the expression of a large number of genes involved with cell cycle kinetics, we found that overexpression of Notch1 resulted in a decrease in cyclin D1 and E levels along with a decrease in Cdk2 level, whereas an increase in p53 level, which might have a direct relevance to the observed $\mathrm{G}_{0} / \mathrm{G}_{1}$ phase arrest in Hep- 2 cells.

Apoptosis is the process of programmed cell death that occurs under numerous physiologic and pathologic conditions. It plays an important role in regulating cell growth, development, immune response and the clearing of redundant or abnormal cells in organisms. The induction and execution of apoptosis require the coordination of a series of molecules, enzymes and gene-regulating proteins. Caspases are interleukin- $1 \beta$ converting enzyme family proteases that initiate apoptosis in mammalian cells. In addition, it is documented 

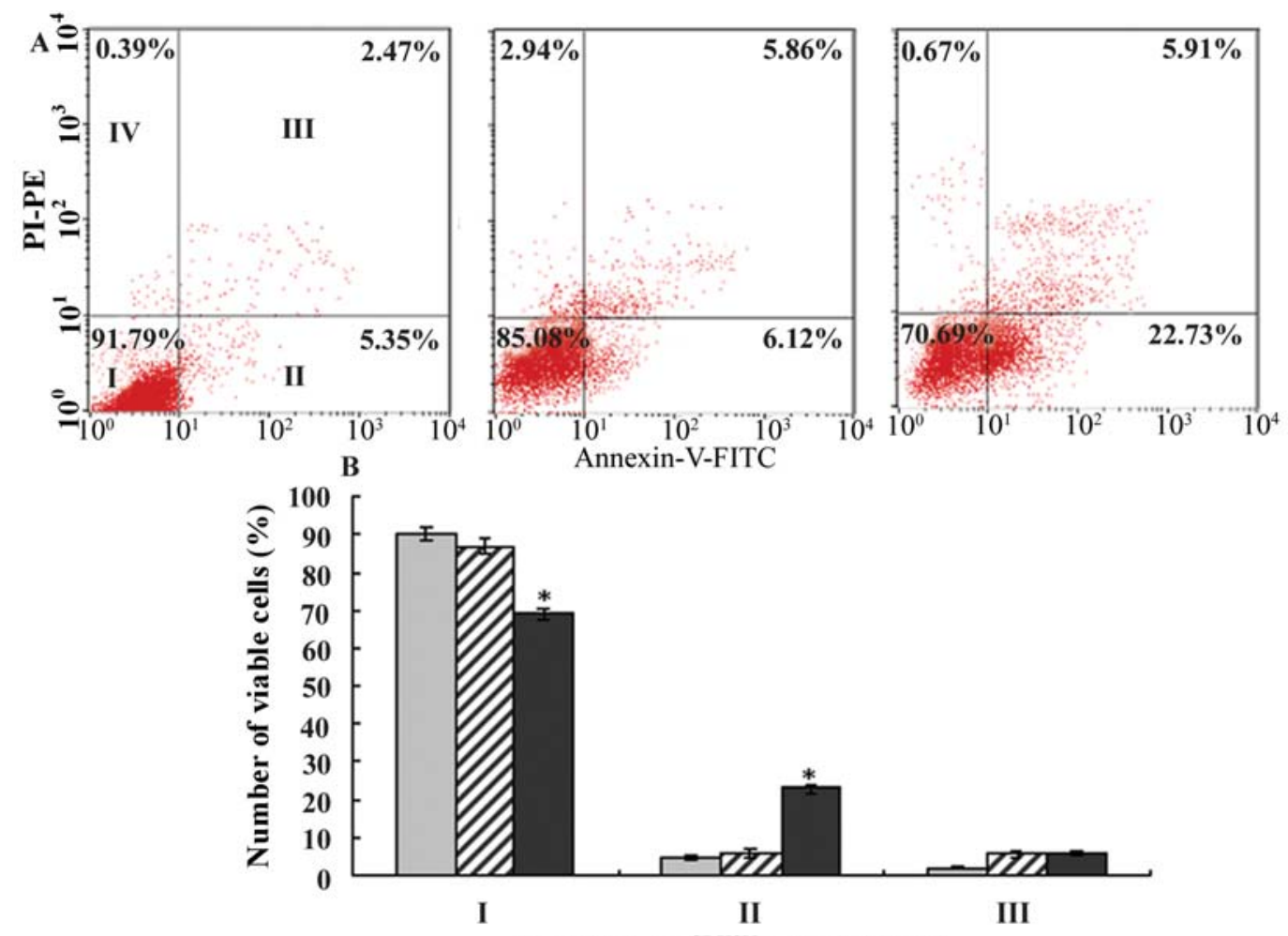

C $\square$ control $\square$ pCLXSN $\square$ pCLXSN-Notch1

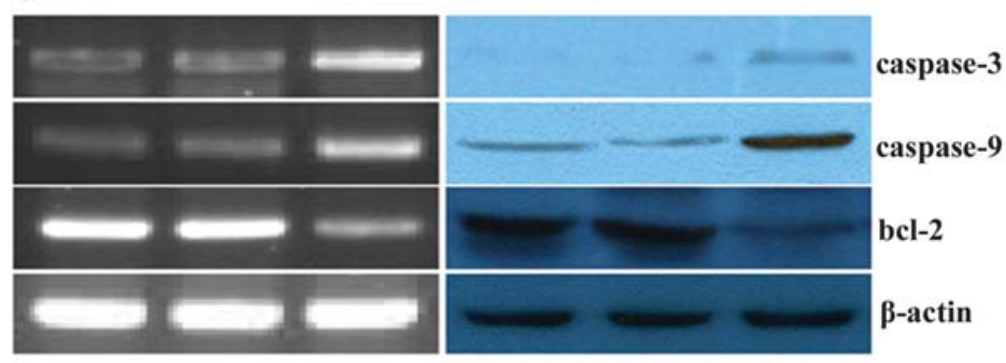

D

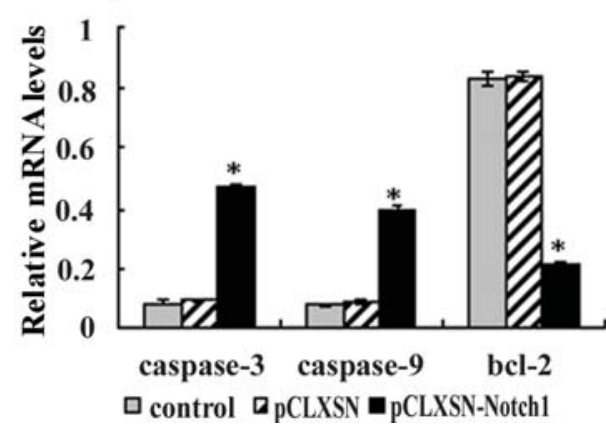

E

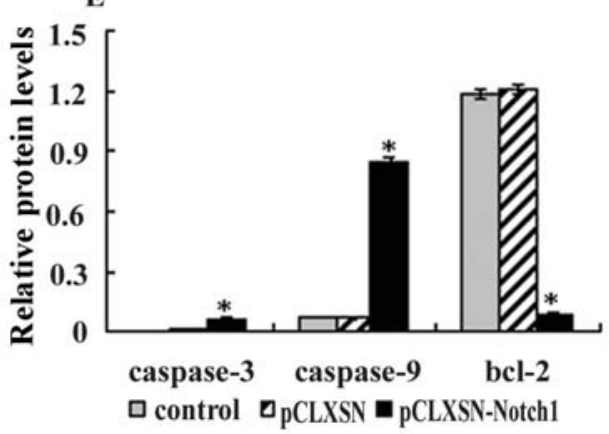

Figure 5. Activation of Notch1 signaling pathway induces cell apoptosis in Hep-2 cells. Hep-2 cells untreated and transfected with pCLXSN and pCLXSNNotch1 were seeded in 6-well plates containing 10\% FBS-RPMI-1640 and harvested at 48 h, respectively, cell apoptosis analysis were performed with flow cytometry, cell apoptosis related molecular markers were investigated by RT-PCR and Western blotting methods. (A) Activation of Notch1 signaling induced cell apoptosis in Hep-2 cells. (B) Results derived from three independent experiments are expressed as means \pm SD. (C) RT-PCR and Western blotting analysis for caspase-3, caspase-9 and bcl-2 expressions in Hep-2 cells. (D) Semi-quantitative values of mRNA levels of caspase-3, caspase-9 and bcl-2 to 3 -actin, respectively. (E) Semi-quantitative values of protein levels of caspase-3, caspase-9 and bcl-2 to $\beta$-actin, respectively. RT-PCR and Western blotting results were from three independently repeated experiments, which were statistically analyzed by densitometry using Gene Tools software, and are expressed as means \pm SD. ${ }^{*} \mathrm{P}<0.05$, compared to those of Hep- 2 cells untreated and transfected with pCLXSN. Results of one representative experiment are reported. Levels of $\beta$-actin are shown for equal loading conditions.

that Notch1 can give rise to cell apoptosis in different cancers $(3,7,14)$, therefore, to directly test whether foreign Notch1 could affect cell apoptosis of laryngeal cancer cell line Hep-2 cells, flow cytometry for analysis of cell apoptosis was performed. Our results showed that extraneous Notch1 could obviously evoke cell apoptosis in Hep-2 cells. Further, we observed increased levels of caspase- 9 and caspase- 3 , which in turn verified the result of flow cytometry. As mentioned 


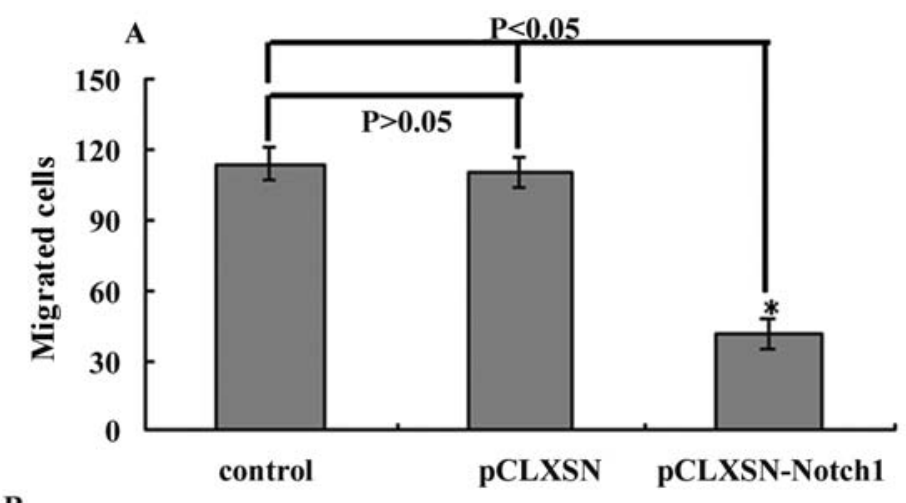

B
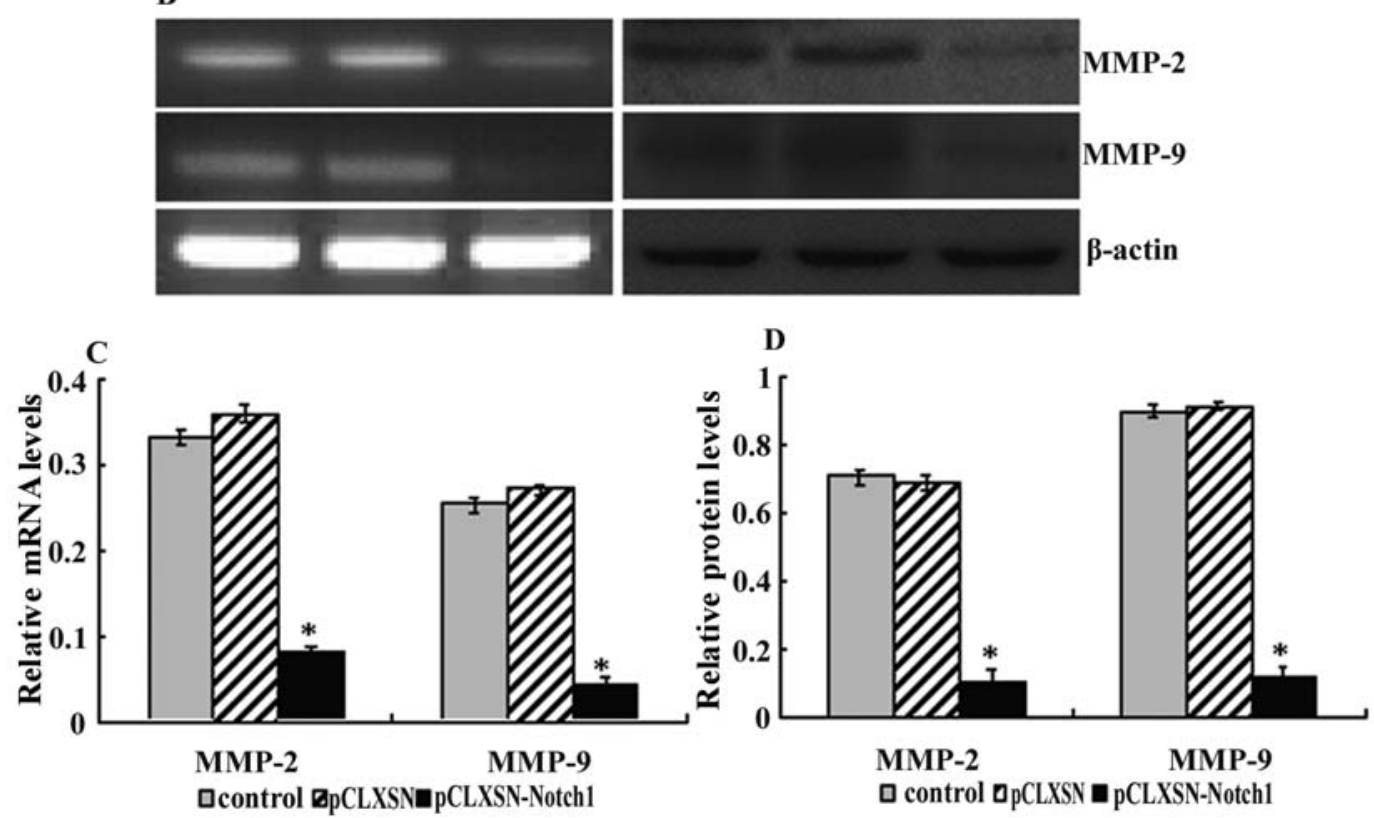

Figure 6. Activation of Notch1 signaling reduces cell invasion and metastasis in Hep-2 cells. Migration of Hep-2 cells was investigated using Boyden chambers with 8- $\mu \mathrm{m}$ pore membrane inserts. Fresh medium 1640 containing 10\% FBS was added to the lower chamber and three groups cells (untreated Hep-2 cells, Hep-2 cells stably expressing empty vector and Notch1) was added to the upper chamber. (A) Activation of Notch1 signaling reduced the migration in Hep-2 cells. (B) RT-PCR and Western blotting methods were used for analysis of MMP-2 and MMP-9 expression. (C) Semi-quantitative values of mRNA levels of MMP-2 and MMP-9 to B-actin, respectively. (D) Semi-quantitative values of protein levels of MMP-2 and MMP-9 to B-actin, respectively. RT-PCR and Western blotting results were from three independent experiments, which were statistically analyzed by densitometry using Gene Tools software, and are expressed as means \pm SD. "Indicates a significant difference compared to control and Hep-2 cells stably expressing empty vector.

earlier, p53 is a tumor suppressor gene and is activated in response to various intrinsic and extrinsic stress signals (22). Activated p53 is a sequence-specific DNA-binding transcriptional factor and some of the target genes of its transcriptional activity are important for cell cycle arrest or for inducing apoptosis (23). For example, p53 regulated genes (Apaf-1, bax, noxa, puma, etc) are known to initiate a protein cascade leading to the activation of caspase- 9 and then caspase- 3 followed by apoptosis $(23,24)$. In addition, several pathways are emerging that depend on external stimuli to signal key molecules in the induction or the prevention of apoptosis. One such pathway is regulated by the expression of the proto-oncogene bcl-2 family, whose members include bcl-2, bcl-x and bax. In the present study, we observed an increase in the level of p53 and a decrease in the level of bcl-2 after transfection with Notch1, which might contribute to the observed cell apoptosis; however, more studies are needed in future to establish such a cause and effect relationship.
Cell migration is critical targets for therapeutic treatment of malignant solid tumors. One key mechanism involved in these pathological processes is the degradation of mechanical barriers represented by specialized extracellular matrices. Tools of election have been found to be some tumor cell-associated proteinases such as matrix metalloproteinases (MMPs) -2 (25) and -9 (26); their expression and activity against matrix macromolecules have been linked to the development of malignant phenotype (27). At present, only one study documented that critical role of Notch signaling in osteosarcoma invasion and metastasis (9). In the current study, the result of Boyden chamber showed that activation of Notch1 signaling could reduce the migration ability of Hep-2 cells, meanwhile, we further determined whether the decreased invasion and metastasis of Hep-2 cells is due to decreased expression of MMPs. It is well documented that MMPs play an important role in cancer promotion and in pulmonary metastasis $(28,29)$. We found that activation of Notch1 signaling could down-regulate the levels of MMP-2 and 
MMP-9, suggesting that a fall of migration ability in Hep-2 cells was probably associated with down-regulation of MMP-2 and MMP-9 expression.

Collectively, our findings demonstrate that activation of Notch1 signaling pathway suppresses proliferation, arrests cell cycle at $\mathrm{G}_{0} / \mathrm{G}_{1}$ phase, induces cell apoptosis and reduces migration ability in Hep- 2 cells coupled with the changes of a large number of genes involved with cell biology behavior, suggesting manipulation of the Notch1 signaling may be of therapeutic value in patients with laryngeal cancer.

\section{References}

1. Vokes EE, Weichselbaum RR, Lippman SM and Hong WK: Head and neck cancer. N Engl J Med 328: 184-194, 1993.

2. Landis SH, Murray T, Bolden S and Wingo PA: Cancer statistics, 1998. CA Cancer J Clin 48: 6-29, 1998.

3. Lu ZM, Liu HT, Xue LX, Xu PR, Gong TX and Hou GQ: An activated Notch1 signaling pathway inhibits cell proliferation and induces apoptosis in human esophageal squamous cell carcinoma cell line EC9706. Int J Oncol 32: 643-651, 2008.

4. Hou GQ, Xue LX, Lu ZM, Fan TL and Xue YL: An activated mTOR/p70S6K signaling pathway in esophageal squamous cell carcinoma cell lines and inhibition of the pathway by rapamycin and siRNA against mTOR. Cancer Lett 253: 236-248, 2007.

5. Artavanis-Tsakonas S, Rand MD and Lake RJ: Notch signaling: cell fate control and signal integration in development. Science 284: 770-776, 1999.

6. Shou J, Ross S, Koeppen H, de Sauvage FJ and Gao WQ: Dynamics of notch expression during murine prostate development and tumorigenesis. Cancer Res 61: 7291-7297, 2001.

7. Morimura T, Goitsuka R, Zhang Y, Saito I, Reth M and Kitamura D: Cell cycle arrest and apoptosis induced by Notch1 in B cells. J Biol Chem 275: 36523-36531, 2000.

8. Sriuranpong V, Borges MW, Ravi RK, Arnold DR, Nelkin BD, Baylin SB and Ball DW: Notch signaling induces cell cycle arrest in small cell lung cancer cells. Cancer Res 61: 32003205,2001

9. Zhang PY, Yang YW, Zweidler-McKay PA and Hughes DPM: Critical role of notch signaling in osteosarcoma invasion and metastasis. Clin Cancer Res 14: 2962-2969, 2008.

10. Retz M, Sidhu SS, Blaveri E, et al: CXCR4 expression reflects tumor progression and regulates motility of bladder cancer cells. Int J Cancer 114: 182-189, 2005.

11. Zang S, Ji Ch, Qu X, et al: A study on Notch signaling in human breast cancer. Neoplasma 54: 304-310, 2007.

12. Maliekal TT, Bajaj J, Giri V, Subramanyam D and Krishna S: The role of Notch signaling in human cervical cancer: implications for solid tumors. Oncogene 27: 5110-5114, 2008.
13. Reedijk M, Odorcic S, Zhang H, et al: Activation of Notch signaling in human colon adenocarcinoma. Int $\mathrm{J}$ Oncol 33: 1223-1229, 2008.

14. Wand Z, Zhang Y, Li Y, Banerjee S, Liao J and Sarkar FH: Down-regulation of Notch-1 contributes to cell growth inhibition and apoptosis in pancreatic cancer cells. Mol Cancer Ther 5: 483-493, 2006.

15. Scorey N, Fraser SP, Patel P, Pridgeon C, Dallman MJ and Djamgoz MB: Notch signaling and voltage-gated $\mathrm{Na}^{+}$channel activity in human prostate cancer cells: independent modulation of in vitro motility. Prostate Cancer Prostatic Dis 9: 399-406, 2006.

16. Fan X, Mikolaenko I, Elhassan I, et al: Notch1 and notch2 have opposite effects on embryonal brain tumor growth. Cancer Res 64: 7787-7793, 2004.

17. Sherr CJ: D-type cyclins. Trends Biochem Sci 20: 187-190, 1995.

18. Donnellan R and Chetty R: Cyclin E in human cancers. FASEB J 13: 773-780, 1999

19. Donnellan R and Chetty R: Cyclin D1 and human neoplasia. Mol Pathol 51: 1-7, 1998.

20. Husdal A, Bukholm G and Bukholm IR: The prognostic value and overexpression of cyclin $\mathrm{A}$ is correlated with gene amplification of both cyclin A and cyclin $\mathrm{E}$ in breast cancer patient. Cell Oncol 28: 107-116, 2006.

21. Keyomarsi K and Pardee AB: Redundant cyclin overexpression and gene amplification in breast cancer cells. Proc Natl Acad Sci USA 90: 1112-1116, 1993.

22. Jin S and Levine AJ: The p53 functional circuit. J Cell Sci 114: 4139-4140, 2001.

23. Harris SL and Levine AJ: The p53 pathway: positive and negative feedback loops. Oncogene 24: 2899-2908, 2005.

24. Yu J and Zhang L: The transcriptional targets of p53 in apoptosis control. Biochem Biophys Res Commun 331: 851-858, 2005.

25. Liotta LA, Tryggvason K, Garbisa S, Hart I, Foltz CM and Shafie S: Metastatic potential correlates with enzymatic degradation of basement membrane collagen. Nature 284: 67-68, 1980.

26. Watanabe H, Nakanishi I, Yamashita K, Hayakawa T and Okada Y: Matrix metalloproteinase-9 (92 kDa gelatinase/type IV collagenase) from U937 monoblastoid cells: correlation with cellular invasion. J Cell Sci 104: 991-999, 1993.

27. Azzam HS, Arand G, Lippman ME and Thompson EW: Association of MMP-2 activation potential with metastatic progression in human breast cancer cell lines independent of MMP-2 production. J Natl Cancer Inst 85: 1758-1764, 1993.

28. Deryugina EI and Quigley JP: Matrix metalloproteinases and tumor metastasis. Cancer Metastasis Rev 25: 9-34, 2006.

29. Hiratsuka S, Nakamura K, Iwai S, et al: MMP9 induction by vascular endothelial growth factor receptor-1 is involved in lung-specific metastasis. Cancer Cell 2: 289-300, 2002. 